\title{
La valoración de los daños arqueológicos y la justicia cautelar en el proceso penal
}

Antonio Roma Valdés, Fiscalía de Santiago de Compostela

\section{INTRODUCCIÓN}

La existencia de un derecho penal que protege el patrimonio cultural es una necesidad, la aplicación de este sector del ordenamiento jurídico es una tragedia, unas veces el reflejo de una pérdida de información insustituible y casi siempre el reflejo de una actuación insensible. La puesta en práctica del Código Penal a la materia propia del patrimonio cultural no es fácil de comprender por quienes dedican su trabajo a recuperar y a potenciar en el futuro este acervo común por varias razones: la primera, que partimos no de la belleza de una obra pasada sino de su destrucción en el presente; la segunda, que es labor de otros técnicos, jurídicos, que emplean una técnica distinta a la propia del derecho que establece el régimen jurídico del patrimonio cultural. Partamos de una premisa, a saber, el derecho penal no regula la protección de determinados bienes sino qué sanción imponer al infractor penal.

En este trabajo se expondrán dos aspectos relativos al funcionamiento del Código Penal, uno tiene que ver con la forma de interpretación de los delitos y faltas penales vigentes, otro con las consecuencias aplicables a quien ha traspasado los limites del sistema. En ambos casos el objeto de atención es una forma especial de patrimonio cultural, el arqueológico, cuya configuración legal y científica tiene unas particularidades que son tenidas en cuenta en la interpretación de la doctrina y la jurisprudencia españolas.

\section{LA VALORACIÓN DE LOS DAÑOS ARQUEOLÓGICOS}

El Código Penal español de 1995 es una norma muy necesitada de reforma en la protección del patrimonio cultural. Sus artículos 323,324 y 325 establecen un régimen de los delitos de daños que determina el castigo tanto de los delitos dolosos como de los cometidos mediante imprudencia, en ambos casos cuando el importe de los desperfectos exceda de la cifra de 400 euros. Su comisión implica la intervención de los órganos jurisdiccionales

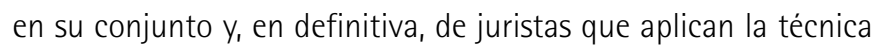
jurídica, que exige la acreditación de todos los elementos del delito comprendiendo, inevitablemente, su importe.
Pero la necesidad de determinación del importe de los daños no deriva únicamente del derecho penal toda vez que la legislación que regula el régimen administrativo del patrimonio cultural hace depender el importe de la sanción. Este es el caso de la Ley 16/1985, de 25 de junio, del patrimonio histórico español, al establecer en su artículo 76.2 que cuando la lesión al patrimonio histórico español ocasionada por las infracciones a que se refiere el apartado anterior sea valorable económicamente, la infracción será sancionada con multa proporcional a su valor. Afortunadamente, éste no es el caso de la actual Ley 14/2007, de 26 de noviembre, del patrimonio histórico de Andalucia, cuyo artículo 114 no hace depender de esta cuantificación el importe de la sanción. Sí lo es, como contrapartida, de una gran mayoría de leyes de comunidades autónomas, tributarias de un régimen cuya principal consecuencia será la de aplicar un régimen primario de sanción que implica cuantificar el daño sobre el bien y uno supletorio consistente en aplicar el montante previsto en la ley para cuando no es posible concretar el valor del desperfecto.

Claro está que una gran parte de los daños son, en abstracto, fáciles de medir. Pensemos en los causados en un cuadro o en un edificio y no veremos inconveniente en pensar que existen técnicas o fórmulas económicas para alcanzar un importante grado de concreción. Sin embargo, la situación se transforma cuando pensamos en el patrimonio arqueológico. Por un lado nos encontramos con que se trata de bienes a los que la legislación administrativa confiere el carácter de dominio público cuando su extracción se produce con posterioridad a la entrada en vigor de la Ley de patrimonio histórico español; por otro, que se trata de un patrimonio por naturaleza ignorado salvo cuando se produce en relación con elementos que por distintas razones han aflorado a la superficie, sin perder por ello la susceptibilidad de estudio a través de la metodología arqueológica. Para un arqueólogo lo importante no es cuánto hay en un yacimiento sino la información que transmite, excediendo notablemente el valor del conjunto al de la suma de los elementos materiales que lo integran. Y aqui surge el desencuentro. Los jueces y fiscales encargados de instruir los delitos que afectan al patrimonio cultural reclaman de arqueólogos informes periciales relativos al valor de los desperfectos ocasionados en un 

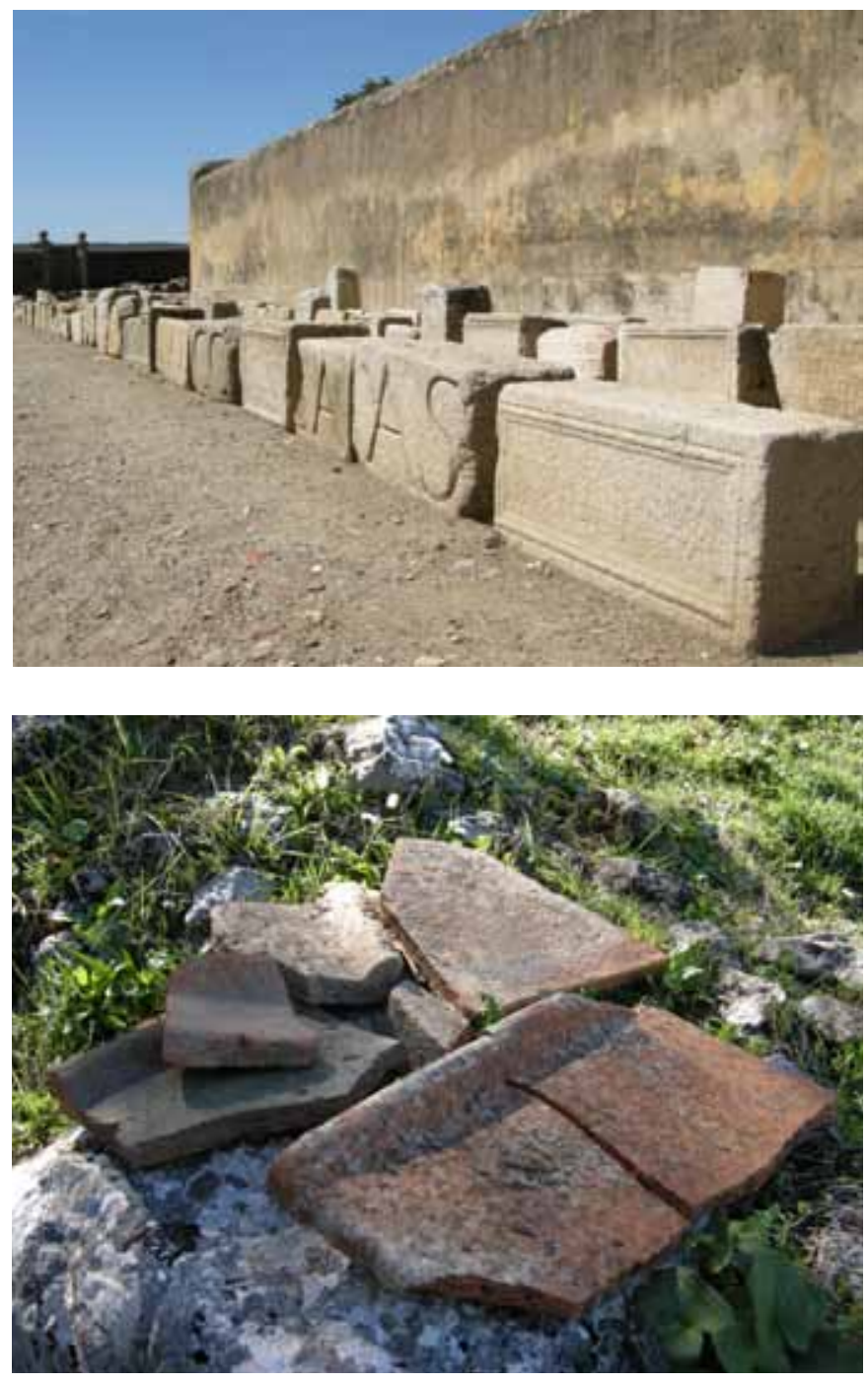

Los daños en el patrimonio arqueológico son difíciles de valorar en términos económicos. Fotos: Jaime Moreno Tamarán

yacimiento arqueológico y éstos, extrañados, no encuentran argumentos científicos para cumplir con ese cometido. Sin duda la redacción de la normativa aludida no es respetuosa con la ciencia arqueológica toda vez que la existencia de la cuantía no resulta a priori necesaria en derecho, por lo demás una técnica de conversión en términos económicos. Precisamente el Código Penal protege la información arqueológica presente en un yacimiento. De una manera más concreta Jesús Garcia Calderón (2008: 82) acude al concepto de valor incalculable que debe orientar la legislación en la materia. Pero ahí está después de tantos años esperando una reforma. No podemos olvidar que no es el único supuesto en el que los tribunales valoran bienes imponderables, pues la cuantificación se realiza a diario al determinar el importe correspondiente a las lesiones corporales y a la propia vida. Basta la lectura del baremo de valoración de las indemnizaciones por muerte, lesiones e incapacidades padecidos por personas que sufren accidentes de tráfico, actualizado anualmente en el Boletín Oficial del Estado para ver la capacidad fría del derecho de poner el valor a la pérdida de visión, falanges de dedos, etc.
Los tribunales y los juristas no han resuelto de una manera uniforme esta dificultad. La sentencia del Tribunal Supremo de 29 de enero de 1997 considera que la imposibilidad de estudio del yacimiento arqueológico por su carácter incalculable determina que el importe de los desperfectos debe ser tenido como notoriamente superior a la cuantía establecida en el Código Penal. Sin embargo, la letra de la ley vigente obliga a determinar de una manera más concreta los daños, al entender de la mayor parte de la doctrina.

Los sistemas de valoración que se han apuntado tienen en común un factor. Todos acuden al valor de la intervención arqueológica como elemento fundamental para apreciar el importe de los desperfectos producidos en un yacimiento, pues es precisamente la intervención la única forma de averiguar la medida de la información arqueológica perdida. En palabras de Grau Lobo (2009: 194), son los gastos que no se tenían que haber producido de no haberse ocasionado la actuación dañina. Ésta es la opinión de Rodríguez Temiño (2012, en prensa), de las conclusiones de fiscales especialistas en medio ambiente y urbanismo de España reunidos en Madrid en 2011 y del que suscribe (ROMA, 2009). Dentro de este conjunto existe una importante coincidencia, con ligeras variaciones, en torno a qué gastos comprende la intervención arqueológica, a saber:

- Los gastos personales y materiales que implica la remoción de tierras, gastos que deben incrementarse en el traslado de al menos una porción de la misma a un vertedero autorizado.

- Los gastos derivados del levantamiento topográfico.

- Los gastos del personal técnico encargado de la actividad arqueológica a realizar no sólo en la excavación sino también en la conservación del material o en la elaboración de la memoria, dentro de los estándares del rigor científico y del respeto a la normativa aplicable (desde la urbanistica a la de seguridad en el trabajo), a determinar en función del tiempo empleado en estas actividades.

Sobre este planteamiento es posible su estimación en función de un coste expresado en euros por metro cúbico que podrá variar en función de la tipología de yacimiento. Y de este cómputo, que dicho sea de paso, en contadas excepciones será inferior a la cuota establecida por el Código Penal, deben quedar fuera, desde mi punto de vista, no compartido por Rodríguez Temiño, los gastos de restauración de los materiales, que se comprenden dentro del concepto jurídico de perjuicio pero no del de desperfecto propiamente dicho.

También existe coincidencia en añadir al importe anterior el precio de los bienes materiales encontrados puesto que, aún perteneciendo al dominio público, su valor de mercado es posible atendiendo al que presentan bienes semejantes en el mercado lícito de los mismos.

Por último, también existe consenso en aplicar un factor de corrección al alza para los supuestos de mayor relevancia del yacimiento atendiendo a su singularidad o monumentalidad, su 
uso público, su interés historiográfico, su estado de conservación previo, etc.

No deja de ser una abstracción, una manera forzada de poner una cifra a un daño incalculable desde el punto de vista de la ciencia arqueológica y que es una derivación de la letra de una legislación que, como indiqué al comienzo, es merecedora de una adaptación a los nuevos tiempos.

No faltan empero sentencias que establecen consecuencias dificiles de asumir. Es el caso de la sentencia de 15 de diciembre de 2008 dictada por el Juzgado de lo Penal número 3 de Vigo, que condenó como autores de una falta contra el patrimonio cultural con una pena de multa leve, sin la posibilidad de establecer consecuencias en el orden civil, a los autores de la destrucción de unas torres medievales situadas en el almacén que regentaban. Su ganancia fue doble, no sólo al conseguir una sanción que el Código Penal clasifica como leve, evitando la aplicación de una sanción administrativa más onerosa, sino que en la actualidad el espacio de almacenamiento es superior. La ausencia de una prueba pericial que informase sobre el importe de los daños explica esta resolución. Por lo tanto, mientras esa reforma deseable no acabe de llegar, es forzoso que los arqueólogos, que son los mejores peritos en la materia, practiquen la pericia y el dar a conocer al juzgado el importe del daño a un yacimiento arqueológico.

\section{MEDIDAS CAUTELARES DEL PATRIMONIO CULTURAL EN EL PROCESO PENAL}

Como se ha podido comprobar, no es sencillo imponer sanciones penales. Se ha afirmado que el sistema penal prefiere un culpable en libertad que un inocente en prisión. Lo cierto es que tanto en la interpretación de la norma como en el sistema de acreditación existen numerosas rigideces y la que se refiere a la determinación del daño en un yacimiento arqueológico es una de ellas. La razón es obvia al establecerse unas sanciones que pueden implicar la pérdida de libertad de las personas. En el caso de los daños al patrimonio histórico o cultural, la pena prevista en el Código Penal es la de prisión entre uno y tres años cuando el delito se comete dolosamente, y de multa de tres a dieciocho meses, atendiendo a la importancia de los daños. En el caso de los delitos dolosos el artículo 323 establece que los jueces o tribunales podrán ordenar, a cargo del autor del daño, la adopción de medidas encaminadas a restaurar, en lo posible, el bien dañado.

Centrada la premisa, corresponde analizar las consecuencias de la infracción desde el punto de vista de la actuación de los órganos jurisdiccionales. Para comenzar debe indicarse que el procedimiento penal se encuentra forzosamente dividido en dos fases, una de instrucción y otra de enjuiciamiento. Dentro de la primera fase, al juez de instrucción le corresponde determinar la existencia de elementos propios de delito y dar traslado de la imputación a quienes aparentan ser los responsables, confiriéndoles una posición procesal que implica el otorgamiento de un conjunto de garantías. Como complemento, el juez debe adoptar las medidas necesarias para garantizar el cumplimiento de una eventual sentencia condenatoria, comprensivas de la situación personal de los imputados estableciendo, en su caso, medidas privativas de libertad que no interesan en este trabajo. Dentro de estas medidas corresponde al instructor adoptar aquéllas tendentes a evitar que el eventual daño se prolongue, así como iniciar las primeras medidas que procuren consolidar el bien (o lo que quede del mismo) o dar comienzo a las que se dirigirán a su restauración. En estos casos será frecuente que el juez dirija un oficio a la Administración competente en materia de patrimonio cultural para que adopte las medidas adecuadas, toda vez que es precisamente esta Administración la que cuenta con el conocimiento, la especialización y la objetividad para resolver de la manera más adecuada, incoando el correspondiente expediente de reposición de la legalidad quebrantada. Por otro lado, podrá acordar las medidas correspondientes para asegurar el pago de las responsabilidades pecuniarias, exigiendo de los responsables fianza, acordando los embargos correspondientes o anotando la incoación del expediente en los registros públicos correspondientes.

El acto de iniciación del procedimiento judicial determina la suspensión de los procedimientos administrativos sancionadores incoados por la administración, siendo frecuente en estos supuestos de daños al patrimonio cultural que existan dos actuaciones en este momento inicial, una administrativa y otra judicial. El aspecto que interesa destacar en este punto es que el procedimiento de reposición de la legalidad de la administración no constituye un expediente sancionatorio, aunque se encuentre vinculado con aquél, de suerte que la existencia de un procedimiento de instrucción judicial no implica un obstáculo ni a su inicio ni a su desarrollo hasta el punto que es posible, como se ha indicado, que sea el propio juez el que comunique la existencia de la infracción a la Administración para que actúe adoptando las medidas más oportunas en protección del bien perjudicado por una infracción penal.

Pero el concepto de cautelaridad no se agota en el procedimiento de instrucción sino que puede extenderse más allá de la sentencia. El artículo 339 del Código Penal, en su redacción otorgada por la Ley Orgánica 5/2010, con entrada en vigor el 23 de diciembre de 2010, mejora la anterior redacción a través de la dicción siguiente: "Los jueces o tribunales ordenarán la adopción, a cargo del autor del hecho, de las medidas necesarias encaminadas a restaurar el equilibrio ecológico perturbado, así como de cualquier otra medida cautelar necesaria para la protección de los bienes tutelados en este título". Este precepto debe ponerse en relación con el artículo 323 del Código Penal, que en su párrafo segundo establece que los tribunales "podrán ordenar, a cargo del autor del hecho, la adopción de medidas a restaurar, en lo posible, el bien dañado". De su lectura puede 


\section{El Código Penal español de 1995}

\section{es una norma muy necesitada de reforma en la protección del patrimonio cultural}

derivarse la obligación de los tribunales de adoptar las medidas cautelares de protección de los bienes tutelados en el Título XVI del Código Penal, patrimonio histórico o cultural incluido. Es por tanto el momento de analizar el significado de este precepto.

Para comenzar, resulta oportuno poner de manifiesto que, frente a la redacción precedente en la que se señalaba que los jueces y tribunales "podrán acordar", la dicción vigente del precepto es claramente imperativa: ordenarán. Lamentablemente, esta reforma no ha alcanzado al artículo 323, fijando un doble régimen, uno imperativo respecto de la reposición de la legalidad y otro aparentemente facultativo referido a la responsabilidad civil de la restauración del bien.

Por otro lado, los destinatarios de la aplicación del artículo 339 son tanto los jueces de instrucción como los órganos jurisdiccionales encargados de dictar y ejecutar las sentencias, lo que se deduce de dos aspectos, el primero que su imposición es independiente y separada de las indemnizaciones derivadas del delito; el segundo, que quienes deben acordar las medidas son los autores del hecho, debiendo subrayarse que el concepto de autor sólo puede deducirse en la sentencia, practicada toda prueba, aunque pueda preverse 0 anticiparse al momento de instrucción. Pese a este planteamiento, son tres las lecturas que ha merecido el precepto:

- Se trata de una medida procesal a aplicar únicamente durante la instrucción judicial.

- Es una medida cautelar equiparada a la responsabilidad civil a imponer en sentencia, pudiendo citarse la sentencia de la Audiencia Provincial de Cádiz de 17 de junio de 2003, que empleó este precepto no en la fase de instrucción sino en la sentencia.

- Es una medida cautelar de carácter análogo a la reposición de la legalidad administrativa quebrantada, a imponer en la sentencia, toda vez que la cautelaridad no se predica del bien dañado, sino del bien jurídico protegido por el Código Penal, en nuestro caso, del patrimonio cultural. Es el criterio de la Audiencia Provincial de A Coruña de 30 de abril de 2004.

La bondad de este último criterio es la más asumible. Pensemos en el caso de la destrucción intencionada de un bien, como las torres medievales aludidas con anterioridad. En el supuesto recogido por la sentencia coruñesa de 30 de abril de 2004 era análoga, en concreto, la destrucción de un yacimiento dirigida a allanar un espacio para su dedicación a actividades turisticas y recreativas. En evitación de una ganancia económica derivada de la ausencia de yacimiento con la sola sanción de una pena pecuniaria, por lo demás no muy elevada, la Audiencia Provincial estableció la prohibición de desarrollar ninguna actividad incompatible con la presencia del yacimiento aunque éste o no existía o se encontraba notablemente perjudicado, extendiendo la cautelaridad más allá del propio procedimiento, al predicarla respecto del bien jurídico (patrimonio cultural arqueológico) por encima del bien inmueble en sí mismo. Como conclusión, indicar que, aunque el procedimiento penal ha mostrado rigideces en su aplicación, cuanto menos desde la vista del ajeno a su funcionamiento, debe reseñarse que ha permitido establecer consecuencias que evitan que la infracción genere un beneficio para el que la ha cometido.

\section{Bibliografía}

CARBALLO ARCEO, X.; DOMÍNGUEZ TEDÍN, M. (2007) A proba pericial e a valoración ao patrimonio cultural. En TAIN GUZMÁN, M. Conxuntos históricos. Propiedade privada e patrimonio público. Santiago de Compostela: Xunta de Galicia, 2007, pp. 151-177

GARCÍA CALDERÓN, J. M. (2003) La protección penal del Patrimonio Arqueológico. Patrimonio cultural y derecho, n. ${ }^{\circ}$ 7, 2003, pp. 99-123

GARCÍA CALDERÓN, J. M. (2005) La protección penal del patrimonio arqueológico. En CORTÉS BECHIARELLI, E.; GARCIA CALDERÓN, J. M.; GUISASOLA LERMA, C. Tres estudios sobre el patrimonio histórico. Sevilla: Junta de Andalucia, 2005, pp. 53-77

GARCÍA CALDERÓN, J. M. (2008) La relación del patrimonio histórico con el derecho penal. En BARRACA DE RAMOS, P. (coord.) La lucha contra el tráfico ilicito de Bienes Culturales. (Curso celebrado en Madrid 16 al 27 de octubre de 2006.) Madrid: Secretaria General Técnica, Subdirección General de Publicaciones, Información y Documentación, Ministerio de Cultura, 2008, pp. 66-84 (recurso publicado también en línea <http://www.mcu.es/patrimonio/docs/MC/LCTI/LCTI_6_ Relacion_Patrimonio_Derecho.pdf> consulta: 15/03/201)

GRAU LOBO, L. (2009) Valoración dos danos ao patrimonio arqueológico. MARTINEZ FERNÁNDEZ, A. (coord.) 0 patrimonio arqueolóxico subacuático e o comercio dos bens culturais: IV Xornadas de protección do patrimonio cultural. Pontevedra: Xunta de Galicia, Consellería de Cultura e Turismo, Dirección Xeral de Patrimonio Cultural, 2009, pp. 180-195

GUISASOLA LERMA, C. (2001) Delitos contra el patrimonio cultural: artículos 321-324 del Código Penal. Valencia: Tirant lo Blanch 2001

NÚÑEZ SÁNCHEZ, A. (2008) El expolio de yacimientos arqueológicos. En BARRACA DE RAMOS, P. (coord.) La lucha contra el tráfico ilicito de Bienes Culturales (Curso celebrado en Madrid 16 al 27 de octubre de 2006.) Madrid: Secretaría General Técnica, Subdirección General de Publicaciones, Información y Documentación, Ministerio de Cultura, 2008, pp. 174-203 (recurso publicado también en línea <http://www.mcu.es/patrimonio/docs/MC/LCTI/LCTI_17_Expolio.pdf> consulta: 15/03/2012)

RENART GARCÍA, F. (2002) El delito de daños al patrimonio cultural español: análisis del art. 323 del código penal de 1995. Granada: Comares, 2002 RODRÍGUEZ TEMIÑO, I. (2012) Indiana Jones sin futuro. Madrid, 2012, en prensa

ROMA VALDÉS, A. (2008) La aplicación de los delitos sobre el patrimonio cultural. Granada: Comares, 2008

ROMA VALDÉS, A. (2009) A determinación da cuantía nos delictos contra o patrimonio arqueolóxico. MARTíNEZ FERNÁNDEZ, A. (coord.) 0 patrimonio arqueolóxico subacuático e o comercio dos bens culturais: IV Xornadas de protección do patrimonio cultural. Pontevedra: Xunta de Galicia, Conselleria de Cultura e Turismo, Dirección Xeral de Patrimonio Cultural, 2009, pp. 138-141 ROMA VALDÉS, A. (2011) Comercio y circulación de bienes culturales. Guía jurídica para profesionales y coleccionistas de arte y antigüedades. Madrid: Difusión Juridica, 2011

SALINERO ALONSO, C. (1997) La protección del patrimonio histórico en el Código Penal de 1995. Barcelona: Cedecs, 1997 